\title{
Journal of Bacteriology and

\section{Field Investigation on Cystic Hydatid Infection in Man and Camel in Tambool Town and Khartoum State Hospitals, Sudan}

Adam Alfaki Mohammad Albadawi ${ }^{1 *}$, Mohammad Eltayeb Ahmed ${ }^{1}$, Nawal Tagelsir Mohammad Osman ${ }^{2}$, Saddig Elowni ${ }^{3}$, Tayseer Elamin Mohammed Elfaki ${ }^{4}$, Asim Abdelrahman Daffalla ${ }^{5}$ and Mohammad Baha Eldin Saad ${ }^{6}$

${ }^{1}$ Department of Parasitology, National Public Health Laboratory (NPHL), Ministry of Health, Republic of Sudan

${ }^{2}$ Department of Molecular Biology, National Health Laboratory (NPHL), Republic of Sudan

${ }^{3}$ Department of Parasitology, Faculty of Medical Veterinary, Sudan University of Science \& Technology, Republic of Sudan

${ }^{4}$ Department of Parasitology, Faculty of Medical Laboratory Science \& Technology, Sudan University of Science \& Technology, Republic of Sudan

${ }^{5}$ Department of Research, Faculty of Science, Abaha University Kingdom Saudi Arabia

${ }^{6}$ Department of Parasitology, Faculty of Medical Laboratory Science, Omdurman Ahlia University, Republic of Sudan

*Corresponding author: Adam Alfaki Mohammad Albadawi, Parasitology Department, National Public Health Laboratory, Ministry of Health, Republic of Sudan, Tel: 249122710595; E-mail: adama027@gmail.com

Received date: March 16, 2016; Accepted date: May 20, 2016; Published date: May 25, 2016

Copyright: (c) 2016 Albadawi AAM, et al. This is an open-access article distributed under the terms of the Creative Commons Attribution License, which permits unrestricted use, distribution, and reproduction in any medium, provided the original author and source are credited.

\begin{abstract}
Echinococcosis/hydatidosis is a zoonotic disease. The disease is caused by adult worms and larval (metacestode) stages of the taeniid cestode Echinococcus granulosus. The life cycle is completed into two hosts. The final host usually carnivore e.g. dog, and the intermediate host usually herbivorous and man. The aim of this study is to evaluate the fertility of cysts and viability of protoscoleces in man and camel hydatid cysts in order to determine the prevalence of their fertility and to study the association with variables typical of host and of the parasite.
\end{abstract}

Material and methods: Across-sectional and observations study was done in biological material (the fluid from human and camel hepatic and lung hydatid cysts). The viability criteria used were ovoid form invaginated scolices and intact calcareous corpuscles. The presence of vibrating movements, and the absence of "vital" staining, the cysts were grouped in diameter cysts from small cysts to very large size of cysts. Descriptive statistics were for the calculation of the prevalence of fertility, analytical statistics for comparison of groups, and multivariate analysis for examination of the association between cyst fertility and clinical variables.

Results: A total of 99 cysts with less than $2 \mathrm{~cm} 5(7.8 \%)$, from 2-6 cm $52(81.2 \%$,) medium diameter $6-10 \mathrm{~cm} 37$ $(57.8 \%)$, and more than $10 \mathrm{~cm} 5(7.8)$, and prevalence of general fertility $68 \%$, sterial cysts was $6 \%$, supporative was $10 \%$ and calcified was $15 \%$. Most of camel fertile cysts had medium size $(81.2 \%)$, while the lowest rate belongs to the small cysts $(7.8 \%)$. There was significant relationship between fertility of the cyst, type of infected organs, type of animals and size of cyst. Association with location, type, and diameter of the cyst, the viability Protoscoleces was assessed by microscopic observation of biological feature represented by muscular movements, flame cell activity in $0.1 \%$ aqueous eosin stain.

Conclusion: The differences between prevalence rates, the fertility of hydatid cysts and diversity sites localization observed in humans and camels. Fertility is associated with the type of cyst, location type, type of animal and size of cyst.

Keywords: Hydatidosis; Field investigation; Hydatid cyst; Sudan

\section{Introduction}

Cystic Echinococcosis (CE)/Hydatidosis is one of important zoonotic diseases caused by larval stage of the dog tapeworm, Echinococcus granulosus. Hydatid disease is most extensively found in East and North Africa, India, Australia, New Zealand, South America, and Middle East including Iran [1-9]. Mostly the rate of the infection in carnivores such as dog and herbivores such as sheep, camels are significant but humans also get the infections accidentally [10-16], hereby, hydatidosis is a major health-economic problem, that has become one of the WHO's active plans for controlling the disease [17].
Larval in man caused hydatid disease, adult worms are only seen in definitive host, dogs, and they cannot develop in man. When the ova are ingested by a suitable intermediate host, they hatch in the duodenum and the oncosphere migrates to the blood stream where it is carried to the liver and others organs of the body. Here it develops into hydatid cyst which consists of an outer thick laminated cyst wall and an inner layer, from the inner layer blood capsules are produced which contain protoscoleces. Fertile hydatid cysts with viable protoscoleces in intermediate hosts are important factors in transferring infection, and stray dogs that wandering around abattoirs; spread the disease due to feeding on infected organs. These factors which differ according to the geographical situation, host and type of infected organs, effect on Echinococcus cycle persistence [17]. Therefore the aim of this survey was to evaluate the fertility of hydatid 
Citation: $\quad$ Albadawi AAM, Ahmed ME, Osman NTM, Elowni S, Elfaki TEM, et al. (2016) Field Investigation on Cystic Hydatid Infection in Man and

Page 2 of 5

cysts and viability of their protoscoleces based on the site, size and type of cysts in slaughtered animals in Tambool, central eastern region of Sudan.

\section{Rationale}

Hydatidosis is known to occur in Sudan in man as well as animals, but the extent of the disease in human population is not known. This is mainly due to the nonspecific clinical presentation and the nonexistence of a sensitive and specific diagnostic methods, a part from confirmation at operation. Therefore this study was undertaken to study the epidemiology of the disease among the human population and to extract antigenic constituents from hydatid cysts in man and attempt to analyses them and use them as targets for different serological tests for the laboratory diagnosis of hydatidosis in man.

\section{Objectives}

To carry out the field investigation of hydatidosis/Echinococcus in Tambool area (The Central Region) and man at hospitals of Khartoum state.

\section{Specific objectives:}

To collected the cysts from internal organs (liver, lungs and other organs) and removed the tissue by scalpel, washed by normal saline five times, aspirate the fluid by syringing in tube $50 \mathrm{ml}$ and centrifuged to separate the protoscoleces and large particle.

\section{Materials and Methods}

\section{Study design}

It is an observational, cross sectional study, was done in biological material (the fluid from human and camel hepatic and lung hydatid cysts).

\section{Study area}

The study was conducted in Tambool town market (Central Eastern of Sudan) which is located $150 \mathrm{Km}$ South East of Khartoum. Al butane area is part of the Central rain lands that provides good grazing for camels, sheep, goats, and cattle stretches from the Ethiopian border in the East to Gezira State in the West roughly occupying the area between isohyets 400 and $700 \mathrm{~mm}$. It comprises 120,000 square kilometers and lies between latitude $13.5^{\circ}-17.5^{\circ} \mathrm{N}$ and longitude $32.4^{\circ}-36.0^{\circ} \mathrm{E}$. It is situated in the rich savanna environment, and second area at hospitals in Khartoum state, and other private clinics.
Specimens were taken from patients who have been already operated or suspected to have hydatidosis.

\section{Sample technique}

The samples collected from 200 slaughtered camels, and fourteen cases were aspirated, (10 liver aspirates, 2 lung aspirate, one abdominal aspirate and a spleen aspirate). Removed hydatid cysts were counted and classified according to the type. Macroscopic characteristics (calcified, suppurative and active), and size $($ small $<2 \mathrm{~cm})$, medium (2-6), large (6-10) and very large (>10). The fluid of active cysts was aseptically aspirated and transferred separately into tubes. After being washed with normal saline, the cyst fluid was centrifuged at $500 \mathrm{rpm}$ for 5 minutes. The precipitate of each sample was observed under a light microscope for cysts. Cysts with no protoscoleces were considered as sterile. Using staining with an aqueous solution of $0.1 \%$ eosin together with considering the motility of flame cell, viability of protoscoleces was assessed in fertile cysts. Viable protoscoleces did not take stain up whereas the dead ones did.

Samples size: $\mathrm{N}=3.840 .25=0.96 \div 0.0025=384$

\section{Study period: the survey was carried out from November 2011-July 2013}

Data was collected by attendant the patient or suspected patient for hydatidosis to the hospital and administered questionnaire information included information of (number, age, sex, marital status, education, level-economic). And for camel at Tambool slaughter house.

\section{Ethical consideration}

Ethical approval for the study was obtained from the Ethical Committee of the federal ministry of health, and permission was provided from all hospitals where investigation was conducted. In addition and informed consent was obtained from each participant prior to interview.

\section{Statistical analysis}

Data were analyzed by using the Statistical Package for Social Science (SPSS) which were presented in below tables and figure.

\section{Results}

The study included a total number of 200 slaughtered camel cysts 53 (26.5), (Table 1) and 14 aspirated from (lung and liver) patients 4 (28.6\%).

\begin{tabular}{|l|l|l|l|l|l|l|}
\hline $\begin{array}{l}\text { Animal } \\
\text { species }\end{array}$ & No. of animal examined & No. of infected animal & Rate of infection & $\begin{array}{l}\text { Total no. of cysts } \\
\text { counted }\end{array}$ & Location of cysts \\
\hline & & & & & Lung & Liver \\
\hline Camels & 200 & 53 & $26.5 \%$ & 99 & $90 / 90 \%$ & $9 / 9 \%$ \\
\hline
\end{tabular}

Table 1: The infection rate of hydatid cyst in camels slaughtered at Tambool during 2011-2013.

Fourteen cases were aspirated (10 liver aspirates, 2 lung aspirate, one abdominal aspirate and a spleen aspirate) (Table 2). Out of the 8 male samples, 2 were found positive while out of the 6 female samples, 2 were found positive. One from the two positive females aged 16 years with a large cyst $(9.8 \times 9.6 \times 8.9 \mathrm{~cm})$ in the right lobe. This was detected by CT scan. The other female was 42 years old with a lung hydatid cyst. The age group of the other patients ranged from $<15$ to $>60$ (Table 3). 
Citation: $\quad$ Albadawi AAM, Ahmed ME, Osman NTM, Elowni S, Elfaki TEM, et al. (2016) Field Investigation on Cystic Hydatid Infection in Man and Camel in Tambool Town and Khartoum State Hospitals, Sudan. J Bacteriol Parasitol 7: 275. doi:10.4172/2155-9597.1000275

Page 3 of 5

\begin{tabular}{|l|l|l|l|l|l|}
\hline Location & Lung & Live $\mathbf{r}$ & Spleen & Abdominal & Total \\
\hline Positive & 2 & 2 & & & 4 \\
\hline Negative & 3 & 5 & 1 & 1 & 10 \\
\hline Total & 5 & 7 & 1 & 1 & 14 \\
\hline
\end{tabular}

with 40x objective. The viability of protoscoleces was tested for each fertile cyst per human camel and organ. For clear vision a drop of 0.1 aqueous eosin solution was added to equal volume of protoscoleces, of hydatid fluid on slide with the Principle that viable protoscoleces should completely or partially exclude the dye, while the dead ones taken up (Figure 1).

Table 2: Aspiration for hydatid cyst among human.

\begin{tabular}{|l|l|l|l|l|l|l|}
\hline Location & $<\mathbf{1 5}$ & $\mathbf{1 6 - 3 0}$ & $\mathbf{3 1 - 4 5}$ & $\mathbf{4 6 - 6 0}$ & $\mathbf{> 6 0}$ & Total \\
\hline Liver & & 1 & 4 & 2 & 3 & 10 \\
\hline Lung & 1 & & 1 & & & 2 \\
\hline Spleen & & & 1 & & & 1 \\
\hline Abdominal & & & & 1 & & 1 \\
\hline Total & 1 & 1 & 6 & 3 & 3 & 14 \\
\hline
\end{tabular}

Table 3: The location of hydatid cyst against age group.

From 8 patients in Khartoum state there were 2 patients positive for hydatid disease. One of 2 patients from Elgedarif state had hydatid cyst in the liver while one 14 year old boy from Elgezira state had hydatid cyst in the lung. All cases from southern and western Darfur were negative for hydatid cyst (Table 4 ). The 4 positive cases were fertile and viable for protoscoleces.

\begin{tabular}{|l|l|l|l|l|l|}
\hline Gender & Liver & Lung & Abdominal & Spleen & Total \\
\hline Male & 5 & 1 & 1 & 1 & 8 \\
\hline Female & 5 & 1 & & & 6 \\
\hline Total & 10 & 2 & 1 & 1 & 14 \\
\hline
\end{tabular}

Table 4: The location of hydatid cyst in different organs.

\section{Examination of cyst fertility \& viability of protoscoleces}

The pressure of the cyst fluid was reduced by using a sterile hypodermic needle. Then the cyst wall was transformed to sterile container and examined microscopically $40 \mathrm{x}$ for the present of protoscoleces. Similarly, the germinal layer was put in glycerin between two microscopic glass slides and examined for the presence of protoscoleces. Cysts which contained no protoscoleces as well as heavily suppurative or calcified were considered infertile. Fertile cysts were subject to viability test, drop of the sediment containing protoscoleces was placed on the microscopic glass slide and covered with a cover slip and observed for amoeboid like peristaltic movements

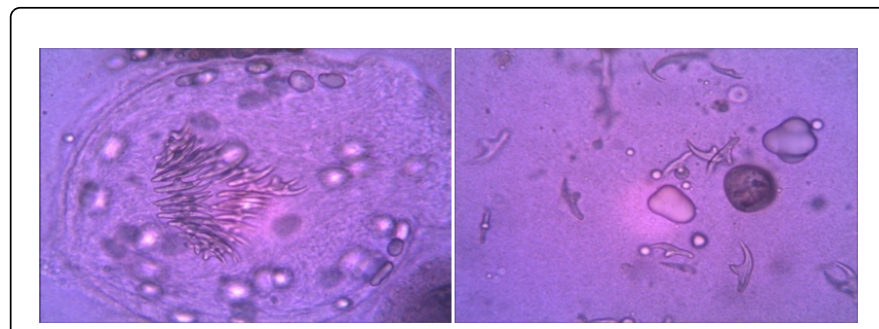

Figure 1: shows the viable protoscoleces and hook let stain by staining with an aqueous solution of $0.1 \%$ eosin.

Most of camel fertile cysts had medium size (81.2\%), while the lowest rate belongs to the small cysts (7.8\%). There was significant relationship between fertility of the cyst, type of infected organs, type of animals and size of cyst (Table 5).

\begin{tabular}{|l|l|l|l|l|l|}
\hline Location & Fertile & Sterile & Calcified & $\begin{array}{l}\text { Viability of } \\
\text { protoscoleces } \\
\text { in fertile cyst }\end{array}$ & Total \\
\hline Lung & $64 / 64.6 \%$ & $5 / 5.1 \%$ & $21 / 21.2 \%$ & $64.6 \%$ & 90 \\
\hline Liver & $4 / 4.0 \%$ & $1 / 1.0 \%$ & $4 / 4.0 \%$ & $4.0 \%$ & 9 \\
\hline Total & $68 / 68.6 \%$ & $6 / 6.1 \%$ & $25 / 25.2 \%$ & $68.6 \%$ & 99 \\
\hline
\end{tabular}

Table 5: Fertility rate of hydatid cysts and viability of protoscoleces of fertile cyst recovered from different organs of camel at Tambool slaughter house.

Also significant difference was observed between viability of camel (lung and liver) cyst protoscoleces $(64.9 \%$ and $4.0 \%)$ respectively. The highest and lowest viability rate seen in small and high size of the cyst. Calcified cysts 15 (15.1) and suppurative cysts 10 (10.1) were the most common type of cysts (15.1\%), and sterile were least (5.1\%), fertile and suppurative cysts allocated the highest percentage of infection. The highest rate of fertility was revealed in camel lung (64.6\%), and the lowest in the liver (4.0\%). Most of sterile, suppurative and calcified cysts were found in camel lung (30.3\%), and least were found in the liver $(5.1 \%)$ the fertility cysts rate and viability of protoscoleces show in (Table 6).

\begin{tabular}{|l|l|l|l|l|l|}
\hline Intermediate host & Organ involved & Total nom. of cyst & $\begin{array}{l}\text { Average of cyst/ } \\
\text { organ }\end{array}$ & $\begin{array}{l}\text { Tt. num. of fertile } \\
\text { cyst }\end{array}$ & $\begin{array}{l}\text { T. num. of sterile } \\
\text { cyst }\end{array}$ \\
\hline Human & Liver & 2 & 1 & $2 / 16.7 \%$ & $3 / 25 \%$ \\
\hline & Lung & 2 & 1 & $2 / 16.7 \%$ & $2 / 16.7 \%$ \\
\hline Camel & Liver & 9 & 2 & $64 / 64.6 \%$ & $5 / 5.1 \%$ \\
\hline
\end{tabular}


Citation: $\quad$ Albadawi AAM, Ahmed ME, Osman NTM, Elowni S, Elfaki TEM, et al. (2016) Field Investigation on Cystic Hydatid Infection in Man and Camel in Tambool Town and Khartoum State Hospitals, Sudan. J Bacteriol Parasitol 7: 275. doi:10.4172/2155-9597.1000275

Page 4 of 5

\begin{tabular}{|l|l|l|l|l|l|l|}
\hline & Lung & 90 & 2 & $4 / 4.0 \%$ & $1 / 1.0 \%$ & $4 / 4.0 \%$ \\
\hline
\end{tabular}

Table 6: Characteristic of human and camel hydatid cysts.

\section{Discussion}

The diagnosis of CE mainly depends on radiological and immunological procedures. Imaging methods are sometimes limited by small size of the lesion and atypical images which are not easy to be distinguished from abscesses or neoplasm. Routine laboratory diagnosis of $\mathrm{CE}$ is dependent on detection of specific antibody response. Serum is generally used for detection of specific antibody although some studies show the detection of antibody in urine might also be a good alternative [18]. The prevalence of CE in human in areas of extensive farming reaches up to 5\% [19]. Therefore, (CE) is particularly important in developing countries, where many nomadic rural inhabitants live under poor sanitary conditions without adequate supplies of clean water and in close proximity to their domestic animals [20]. Echinococcosis is a disease closely related to certain jobs: butchers, farmers, shepherds, and the geographic distribution of the disease follows the curve of the infection in shepherds and is determined by the level of pastoral hygiene [21].

In Sudan several studies documented the endemicity of cystic Echinococcosis in different part of the country [22-25]. The result from this survey is lower than those observed, in the same region, Elmahdi et al. [24] reported prevalence of $44.6 \%, 6.9 \%$ and $3.0 \%$ in camel, sheep and cattle, respectively. The infection rate reported $(16.1 \%)$ is likely reflecting the true epidemiological situation in camel since only one camel infected in age group less than three years. However, the prevalence of E. granulosus is known to be positively correlated with age $[1,26]$.

Cystic Echinococcus (CE) occurs in all continents including circumpolar, temperate, tropical and subtropical and zones ranks in some areas as the leading disease of public health significance [19]. Camel appear to play the major role for the maintenance of $E$. granulosus in Central Sudan, for about $26.5 \%$ of camels examined in this study were found to be infected with cystic Echinococcus with high fertility rate (68\%). Moreover, molecular characterization indicated that camel strain (G6) is more prevalent in this area. Since it had been found in camel, however, in all countries where camel has been reported as an intermediate host, it was too important for the local maintenance of the life cycle [19]. For all examined hydatid cysts, there were significant relations between the type of animals and infected organ with type of cysts. In addition the highest percentage of infection belonged to sterile cysts while calcified cysts possessed the least (Table 6). The presence of protoscoleces either attacked to the germinal layer epithelium in for of browed capsule or either presence in the cyst fluid was considered as indicative of fertility [27]. The viability of protoscoleces was assessed by the mobility of flame cells together with the staining with 0.1 aqueous eosin solution [28]. Furthermore infertile cysts were further classified as sterile characterized by their smooth inner lining usually with slightly turbid fluid in its content. Typical calcified cyst produce a gritty sound feeling up on incision $[29,30]$.

In agreement with our findings [31], in northwestern Ethiopia, reported the sterile cysts as the most prevalent type of removed hydatid cysts [31,32], Additional [32], in Arak province of Iran, found calcified cysts as the least type among all hydatid cysts [31], however opposite to our finding, in Sardinia (Italy) calcified cysts were observed as the most prevalent [33]. In our statistical analysis showed a significant relation of cysts, fertility and their size. Most of fertile hydatid cysts had a medium size in camel lungs (Table 6).

In one case of human cystic Echinococcosis in the Netherlands the Argentina molecular analysis of Echinococcus granulosus isolates encountered from man intermediate host showed for the first time that the camel strain genotype (G6) is infective for human [34-36]. Another study carried out in Mauritania identified the camels strain genotype (G6) in two human samples.

In conclusion can be said that fertility rate of liver and lung hydatid cysts of camel and viability of protoscoleces is considerable. In addition the fertility of hydatid cysts in human was low but they had high viability rate of protoscoleces. Fertility is associated with the type, location and the size of cyst.

\section{Author's Contribution}

Albadawi collected hydatid cyst samples from Tambool slaughter house, and examined macroscopic and microscopic of the cysts. Saad designed the experiment and prepared the final manuscript, Ahmed edited and helped with experimental designed, Nawal analyzed the sequences and designed the study, Elowani and Daffalla edited the sequences and helped with experimental design, Teaser designed the experiment. All authors read and approved the final version of the manuscript.

\section{Acknowledgement}

Authors would like to thanks the colleagues who helped me in performing this study particularly to Ibrahim Elhag Elmahdi, and Abdelmoneim Elhag Elmahdi, for their kind contribution in institute of Nuclear Medicine, Molecular Biology and oncology, University of Gezira, Wad Medani, Sudan. Surgeons in Khartoum hospitals for their cooperation for collecting hydatid cysts samples, this study was made possible by invaluable assistance provided by Mr. Hatim babaker polio. National Public Health Laboratory (NPHL). The authors are very grateful to Mss. Aida Mohammad Khair and Mawaheb Abdelmoneim Mycology department, Khartoum University.

\section{References}

1. Dueger EL, Gilman RH (2001) Prevalence, intensity, and fertility of ovine cystic Echinococcosis in the central Peruvian Andes. Trans R Soc Trop Med Hyg 95: 379-383.

2. Qaqish AM, Nasrieh MA, Al-Qaoud KM, Craig PS, Abdel-Hafez SK (2003) The seroprevalences of cystic echinococcosis, and the associated risk factors, in rural-agricultural, bedouin and semi-bedouin communities in Jordan. Ann Trop Med Parasitol 97: 511-520.

3. Small LM, Pinch DS (2003) Survey for hydatidosis in cattle bred in the northern region of the Northern Territory of Australia. Aust Vet J 81: 355-358.

4. Ahmed S, Nawaz M, Gul R, Zakir M, Razzaq A (2006) Some epidemiological aspects of hydatidosis of lungs and livers of sheep and goats in Quetta, Pakistan. Pakistan J Zool 38:1-6. 
Citation: $\quad$ Albadawi AAM, Ahmed ME, Osman NTM, Elowni S, Elfaki TEM, et al. (2016) Field Investigation on Cystic Hydatid Infection in Man and Camel in Tambool Town and Khartoum State Hospitals, Sudan. J Bacteriol Parasitol 7: 275. doi:10.4172/2155-9597.1000275

Page 5 of 5

5. Dopchiz MC, Elissondo MC, Andresiuk MV, Maiorini E, Gutiérrez AM, et al. (2009) Pediatric hydatidosis in the south-east of the Buenos Aires province, Argentina. Rev Argent Microbiol 41: 105-111.

6. Pednekar RP, Gatne ML, Thompson RC, Traub RJ (2009) Molecular and morphological characterisation of Echinococcus from food producing animals in India. Vet Parasitol 165: 58-65.

7. Saeed I, Kapel C, Saida LA, Willingham L, Nansen P (2000) Epidemiology of Echinococcus granulosus in Arbil province, northern Iraq, 1990-1998. J Helminthol 74: 83-88.

8. Jenkins DJ, Allen L, Goullet M (2008) Encroachment of Echinococcus granulosus into urban areas in eastern Queensland, Australia. Aust Vet J 86: 294-300.

9. Ibrahim MM (2010) Study of cystic Echinococcosis in slaughtered animals in Al Baha region, Saudi Arabia: interaction between some biotic and abiotic factors. Acta Trop 113: 26-33.

10. Daryani A, Alaei R, Arab R, Sharif M, Dehghan MH, et al. (2007) The prevalence, intensity and viability of hydatid cysts in slaughtered animals in the Ardabil province of Northwest Iran. J Helminthol 81: 13-17.

11. Ahmadi NA, Hamidi M (2008) A retrospective analysis of human cystic echinococcosis in Hamedan province, an endemic region of Iran. Ann Trop Med Parasitol 102: 603-609.

12. Sadjjadi SM, Sedaghat F, Hosseini SV, Sarkari B (2009) Serum antigen and antibody detection in echinococcosis: application in serodiagnosis of human hydatidosis. Korean J Parasitol 47: 153-157.

13. Ahmadi NA, Meshkehkar M (2011) An abattoir-based study on the prevalence and economic losses due to cystic echinococcosis in slaughtered herbivores in Ahwaz, south-western Iran. J Helminthol 85: 33-39.

14. Shahnazi M, Hejazi H, Salehi M, Andalib AR (2011) Molecular characterization of human and animal Echinococcus granulosus isolates in Isfahan, Iran. Acta Trop 117: 47-50.

15. Dalimi A, Motamedi G, Hosseini M, Mohammadian B, Malaki H, et al. (2002) Echinococcosis/hydatidosis in western Iran. Vet Parasitol 105: 161-171.

16. Mamishi S, Sagheb S, Pourakbari B (2007) Hydatid disease in Iranian children. J Microbiol Immunol Infect 40: 428-431.

17. Vuitton DA (1997) The WHO Informal Working Group on Echinococcosis. Coordinating Board of the WHO-IWGE. Parassitologia 39: 349-353.

18. Sunita T, Dubey ML, Khurana S, Malla N (2007) Specific antibody detection in serum, urine and saliva samples for the diagnosis of cystic Echinococcosis. Acta Trop 101: 187-191.

19. Schantz PM, Chai PS, Craig DJ, Jenkins CNI, Thakur A (1995) Epidemiology and control of hydatid disease. In Echinococcus and Hydatid Disease, R.C.A. Thompson, A.J. Lymbery (eds.) CAB international, Wallingford, Oxon. Pp: 232-331.

20. Andersen FL (1997) Introduction to cystic Echinococcosis and description of cooperative research project in Morocco. In: Andersen FL, Ouhelli H, Kachani M (eds.): Compendium on Cystic Echinococcosis in Africa and in Medial Eastern Countries with special reference to Morocco. Brigham Young University Provo. UT 84602 USA: 1-17.
21. Burlui D, RoÅŸca M (1977) Chirurgia chistului hidatic hepatic. Liver hydatid cyst surgery. Editura MedicalÄ $f$, Bucharest, Romania.

22. Saad MB, Magzoub M (1989a) Hydatidosis in camels and cattle in the Sudan. Sudan Journal of Veterinary Science Animal Husbandry. 28: 27-32.

23. Saad MB, Magzoub M (1989b) Hydatidosis in Sheep and goats in the Sudan. Sudan Journal of Veterinary Science Animal Husbandry 28: 33 -37 .

24. Elmahdi IE, Ali QM, Magzoub MM, Ibrahim AM, Saad MB, et al. (2004) Cystic Echinococcus of livestock and human in central Sudan. Ann Trop Med Parasitol 98: 473-479.

25. Osman AMA, Aradaib IE, Ashmaig ALK, Gameel AA (2007) Rapid detection of Echinococcus granulosus-complex and specific identification camel genotype (G6) a nested PCR. Proceeding Echinococcus of the 22nd International Congress of Hydatiology, Athens, Greece. pp: 80-85.

26. Lahmar S, Kilani M, Torgerson PR, Gemmell MA (1999) Echinococcus granulosus larvae in the livers of sheep in Tunisia: the effects of host age. Ann Trop Med Parasitol 93: 75-81.

27. Macpherson CN, Zeyhle E, Romig T (1984) An Echinococcus pilot control programme for north-west Turkana, Kenya. Ann Trop Med Parasitol 78: 188-192.

28. Smyth JD, Barrett NJ (1980) Procedures for testing the viability of human hydatid cysts following surgical removal, especially after chemotherapy. Trans R Soc Trop Med Hyg 74: 649-652.

29. Soulsby EjL (1982) Helminthes, arthropod and protozoa of domestic animals. (7thedn. Lea and Foleyer, philadphia).

30. Parija SC (2004) Text book USA medical parasitology, Protozology and helminthology. 2ndedn. India publishers and distributors.

31. Kebede N, Mitiku A, Tilahun G (2009) Hydatidosis of slaughtered animals in Bahir Dar Abattoir, Northwestern Ethiopia. Trop Anim Health Prod 41: 43-50.

32. Mohebali M, Sammak A (1996) A survey on the Hydatidosis in human and Hydatid cyst in rearing livestocks which were slaughtered in Arak slaughter house. J Kerman Univ Med Sci 3: 46-48.

33. Scala A, Garippa G, Varcasia A, Tranquillo VM, Genchi C (2006) Cystic echinococcosis in slaughtered sheep in Sardinia (Italy). Vet Parasitol 135: 33-38.

34. Rosenzvit MC, Zhang LH, Kamenetzky L, Canova SG, Guarnera EA, et al. (1999) Genetic variation and epidemiology of Echinococcus granulosus in Argentina. Parasitology 118: 523-530.

35. Schantz PM (1997) Sources and uses of surveillance data for cystic Echinococcosis. In: Anderson FL, Ouhelli H, Kachani M, (eds.) Compendium on Cystic Echinococcosis, in Africa and Middle Eastern Countries with the reference to Morocco, Brigham Young University. Provo, UT 84602, USA. pp: 72-84.

36. Dopchiz MC, Elissondo MC, Andresiuk MV, Maiorini E, Gutiérrez AM, et al. (2009) Pediatric hydatidosis in the south-east of the Buenos Aires province, Argentina. Rev Argent Microbiol 41: 105-111. 